\title{
Lack of correlation between serum 25(OH)D level and endoscopy-based chronic rhinosinusitis in Korean adults*
}

\author{
Eun Jung Lee ${ }^{1,2}$, Chi Sang Hwang ${ }^{3}$, Kyung-Su Kim¹ \\ ' Department of Otorhinolaryngology, Yonsei University College of Medicine, Seoul, Korea \\ 2 The Centre for Personalised Medicine and Division of Pediatrics, Department of Clinical and Experimental Medicine, Linkoping, \\ Sweden \\ ${ }^{3}$ Department of Otorhinolaryngology, Yonsei University Wonju College of Medicine, Wonju, Korea
}

\author{
Rhinology 57: 2, $139-146,2019$ \\ https://doi.org/10.4193/Rhin18.110 \\ * Received for publication: \\ May 24, 2018 \\ Accepted: September 10, 2018
}

Background: Several previous studies have shown that serum 25(OH)D deficiency is associated with increased risk of chronic rhinosinusitis (CRS) in adults and also correlated with disease severity. We aimed to investigate the correlation between serum 25(OH)D level and endoscopy-based CRS in adults using the Korean National Health and Nutrition Examination Survey.

Methods: The data were based on the Korean National Health and Nutrition Examination Survey from 2008 to 2011. Diagnosis of endoscopy-based CRS was based on endoscopic findings of mucopurulent rhinorrhea in the middle meatus or nasal polyps, with nasal symptoms satisfying symptom-based CRS based on European Position Paper on Rhinosinusitis and Nasal Polyps 2012 criteria. Nasal symptoms included nasal obstruction, anterior/posterior nasal drip, facial pain, and the loss of smell. Serum $25(\mathrm{OH})$ D level was defined as deficient $(<20 \mathrm{ng} / \mathrm{mL})$, insufficient $(20-29.9 \mathrm{ng} / \mathrm{mL})$, or sufficient $(\geq 30 \mathrm{ng} / \mathrm{mL})$.

Results: The serum 25(OH)D level in the CRS group was $19.293 \pm 7.035 \mathrm{ng} / \mathrm{mL}$, which was higher than that of the control group $(18.057 \pm 6.56 \mathrm{ng} / \mathrm{mL}, \mathrm{p}=0.0072)$. Among symptom combinations of endoscopy-based CRS, some combinations with mucopurulent rhinorrhea at the middle meatus were significantly related to normal serum $25(\mathrm{OH}) \mathrm{D}$ level.

Conclusion: Low serum 25(OH)D level might not be associated with increased prevalence of CRS in Korean adults; rather, patients with CRS showed higher serum 25(OH)D levels than the control group. Thus, these results, contradicting those of previous studies, should be further verified in other countries to investigate the role of the serum 25(OH)D in CRS.

Key words: epidemiology, rhinosinusitis, 25(OH)D, endoscopy, mucopurulent rhinorrhea, nasal polyp

\section{Introduction}

Beyond its pivotal role in bone mineralization, recent studies have shown that $25(\mathrm{OH}) \mathrm{D}$ deficiency is associated with an increase in upper airway diseases such as allergic rhinitis and asth$\mathrm{ma}^{(1-3)}$. Nutritional studies in pregnancy indicate that increasing maternal consumption of $25(\mathrm{OH}) \mathrm{D}$ decreases the risk of asthma in newborn babies, suggesting that in utero exposure to $25(\mathrm{OH})$ D might activate protective mechanisms in the developing immune system $^{(4)}$. There is increasing evidence indicating that $25(\mathrm{OH}) \mathrm{D}$ supplementation in people who are 25(OH)D deficient can provide protection against respiratory infection ${ }^{(5,6)}$. Through its effects on the immune system, serum $25(\mathrm{OH}) \mathrm{D}$ could play an important role in the pathogenesis of upper airway diseases such as chronic sinusitis.

Chronic rhinosinusitis (CRS) is one of the most prevalent chronic diseases, characterized by the inflammation of the paranasal sinus mucosa for 12 consecutive weeks or more. Although insights into the pathogenesis of CRS have largely expanded over recent years, the exact etiology and mechanism are still unknown. Not only does 25(OH)D support immune function, regulate cell growth, and help reducing inflammation, but several recent reports have also shown a link between the increase of CRS and 25(OH)D deficiency ${ }^{(7-9)}$. In some studies, serum $25(\mathrm{OH})$ $D$ levels were found to be lower in patients with CRS and to correlate with disease severity ${ }^{(9)}$. However, these previous studies were conducted only in Western populations and included small 
sample sizes, which may have influenced the results and its significance. Therefore, the aim of this study was to investigate the association between serum 25(OH)D level and CRS diagnosed with endoscopy-based European Position Paper on Rhinosinusitis and Nasal Polyps (EP3OS) 2012 criteria using the data from the 2008 to 2011 Korean National Health and Nutrition Examination Survey (KNHANES) in adults from South Korea.

\section{Materials and methods}

Subjects and survey methods

KNHANES is a complex survey because the data were not obtained using a simple random sample. Rather, a complex, multistaged, probability sampling design was used to select participants. Within the visiting survey team, a resident of the Korean Society of Otorhinolaryngology-Head \& Neck Surgery was included. At least second-year residents of the Korean Society of Otorhinolaryngology-Head \& Neck Surgery performed the endoscopic examinations. Standardization of the endoscopic examinations in KNHANES was performed as previously described $^{(10)}$. Baseline information for each population was obtained using a structured questionnaire administered by trained interviewers. After the baseline survey, the residents asked more specific questions on the questionnaire concerning the following nasal symptoms: mucopurulent discharge, nasal obstruction/ congestion, facial pain/pressure, and dysosmia lasting longer than 3 months. At the same time, the residents performed a physical examination on individuals aged 12 years or older using a 4-mm, $0^{\circ}$ rigid nasal endoscope in a well-equipped mobile medical examination bus. Nasal endoscopic examination was performed 5 minutes after applying a topical vasoconstrictor $(0.5 \%$ Neo-Synephrine $:$ distilled water $=1: 1)$.

\section{Informed consent and Ethics Committee Review approval} This study was reviewed and approved by the Institutional Review Board (IRB) in accordance with the Helsinki Declaration. The survey protocol was approved by the IRB of the Korea Centers for Disease Control and Prevention. The IRB approval numbers are 2008-04EXP-01-C, 2009-01CON-03-2C, 2010-02CON21-C, and 2011-02CON-06-C.

\section{Definition of CRS}

We assessed the prevalence of CRS based on the diagnostic criteria of endoscopy-based CRS. The diagnosis of endoscopybased CRS was done as a diagnosis based on endoscopic findings of mucopurulent rhinorrhea in the middle meatus (AF1) or nasal polyps (AF2), with nasal symptoms meeting the definition criteria of symptom-based CRS. For endoscopic examination, AF1 was defined as mucopurulent rhinorrhea at middle meatus, and AF2 was defined as nasal polyp in the nasal cavity. AF3 was defined as other tumors except nasal polyp. We included AF1 and AF2 for the diagnosis of endoscopy-based CRS. The questi-
Table 1. Definition of CRS based on different diagnostic criteria.

$\mathrm{CRS}=$ chronic rhinosinusitis

onnaires assessed symptoms such as nasal blockage or obstruction or congestion, anterior/posterior nasal drip, facial pain, and loss of smell. Symptom-based CRS was defined using the EP3OS 2012 diagnostic criteria for epidemiological studies (Table 1).

\section{Measurement of serum 25(OH)D level}

Blood samples were obtained after a 12-h overnight fast. The serum $25(\mathrm{OH}) \mathrm{D}$ level was measured by radioimmunoassay using a 25(OH)D 125 I radioimmunoassay kit (DiaSorin, Stillwater, Oklahoma, USA). The radioimmunoassay was performed with the 1470 WIZARD gamma counter (PerkinElmer, Turku, Finland). Subjects were categorized into three groups according to serum 25(OH)D level. Serum 25(OH)D levels below $20 \mathrm{ng} / \mathrm{mL}$ $(50 \mathrm{nmol} / \mathrm{L})$ were defined as deficiency, levels ranging from 20 to $29.9 \mathrm{ng} / \mathrm{mL}(50-74 \mathrm{nmol} / \mathrm{L})$ were defined as insufficiency, and levels above $30 \mathrm{ng} / \mathrm{mL}$ ( $75 \mathrm{nmol} / \mathrm{L}$ ) were defined as sufficiency according to the criteria of the endocrine society ${ }^{(11)}$.

\section{Demographic factors}

The statistical association between $25(\mathrm{OH}) \mathrm{D}$ level and demographic factors was analyzed. Demographic factors included clinically relevant sociodemographic and personal medical factors. The factors we considered were based on previous epidemiological studies regarding CRS, from which we chose 11 variables. Factors included sex, age, smoking, education, stress, obesity, hypertension, diabetes mellitus, bronchial asthma, allergic rhinitis, and stroke. Additionally, we added calcium intake, cholesterol level, and $\mathrm{HbA} 1 \mathrm{c}$ level. Age, calcium intake, cholesterol level, and $\mathrm{HbA} 1 \mathrm{c}$ level were set as numerical variables, and the other factors were set as categorical variables. All variables were defined based on the answers to the questionnaire and the blood chemistry data (Table 2). The details for categorizing each factor and the diagnosis of each disease were described previously ${ }^{(10)}$. 
Table 2. Definition of factors applied in the analysis.

\begin{tabular}{|c|c|}
\hline Variables & Definitions \\
\hline Sex & Male / female \\
\hline Age & Based on American age \\
\hline \multirow[t]{2}{*}{ Smoking } & (-): former smokers or nonsmokers \\
\hline & $(+)$ : current smokers \\
\hline Obesity & $(-)$ or (+): based on BMI \\
\hline \multirow[t]{2}{*}{ Education } & Low: graduated middle \& high school \\
\hline & High: graduated university \\
\hline Stress & $\begin{array}{l}\text { Light or heavy: subjective feelings of stress in } \\
\text { daily life }\end{array}$ \\
\hline Hypertension & $\begin{array}{l}(-) \text { or }(+) \text { : history of hypertension diagnosed by a } \\
\text { doctor }\end{array}$ \\
\hline Diabetes mellitus & $\begin{array}{l}(-) \text { or }(+) \text { : history of diabetes mellitus diagnosed } \\
\text { by a doctor }\end{array}$ \\
\hline Stroke & (-) or (+): history of stroke diagnosed by a doctor \\
\hline Bronchial asthma & $\begin{array}{l}(-) \text { or }(+) \text { : history of bronchial asthma diagnosed } \\
\text { by a doctor }\end{array}$ \\
\hline Allergic rhinitis & $\begin{array}{l}\text { (-) or (+): history of allergic rhinitis diagnosed by } \\
\text { a doctor }\end{array}$ \\
\hline Calcium intake & The amount of calcium intake / 1day (mg) \\
\hline Cholesterol & Based on enzyme method \\
\hline $\mathrm{HbA1c}$ & $\begin{array}{l}\text { Based on high performance liquid chromato- } \\
\text { graphy }\end{array}$ \\
\hline
\end{tabular}

\section{Statistical analysis}

To estimate the entire non-institutionalized Korean population from the survey sample, the KNHANES sampling weight variables, masked variance primary sampling unit, and stratum variables were used. Survey sample weights were used in all analyses. The data were analyzed with SAS software (version 9.2, SAS Institute Inc., Cary, NC, USA) in order to incorporate sample weights and adjust the analysis for the complex sample design of the survey. The prevalence of CRS based on diagnostic criteria was estimated, and the differences of serum 25(OH)D level between each group were statistically analyzed using the independent two-sample t-test and chi-square test as appropriate. While the independent two-sample t-test was performed using $25(\mathrm{OH}) \mathrm{D}$ level as a continuous variable, the chi-square test was performed using $25(\mathrm{OH}) \mathrm{D}$ level as a categorical variable. Univariate cumulative logistic regression (clogit) analysis was performed with the $25(\mathrm{OH}) \mathrm{D}$ level variable to calculate adjusted odds ratios (ORs) and their 95\% confidence intervals (Cls). To perform cumulative logistic regression, we formed two groups according to $25(\mathrm{OH}) \mathrm{D}$ level: the normal group included sufficient and insufficient $25(\mathrm{OH}) \mathrm{D}$ groups, and the abnormal group included the deficient $25(\mathrm{OH}) \mathrm{D}$ group. The analysis was performed on each CRS diagnostic criteria set. After univariate logistic regression, multivariate logistic regression using stepwise selection method was performed to confirm significant variables. A p- value $<0.05$ was considered statistically significant.

\section{Results}

\section{Demographic data}

A total of 30,609 individuals aged 19 years or older from 38,638 paricipants in 4,000 households was chosen in the KNHANES from January 2008 to December 2011, and these randomly selected participants represented the general population of South Korea. The male-to-female ratio was 1:1.32, and the mean age was $49.85 \pm 16.78$ years. There were 1,712 subjects in the $25(\mathrm{OH})$ D sufficient group, 8,412 in the $25(\mathrm{OH}) \mathrm{D}$ insufficient group, and 20,485 in the $25(\mathrm{OH}) \mathrm{D}$ deficient group according to $25(\mathrm{OH}) \mathrm{D}$ level. An endoscopy-based diagnosis of CRS was done for 645 subjects ( $2.11 \%$ of total subjects). We evaluated the possible effects of demographic factors on serum 25(OH)D level, and all factors except bronchial asthma showed statistically significant difference for three groups (Table 3). We ran univariate logistic regression on all of the confounding factors, and found that all variables were significant. After multivariate logistic regression using stepwise selection method, we identified that female sex low age, and allergic rhinitis were significant factors showing lower 25(OH)D levels (Table 4).

\section{Comparison of 25(OH)D level between CRS group and con- trol group}

When considering serum $25(\mathrm{OH}) \mathrm{D}$ level as a continuous variable, the serum 25(OH)D level in the CRS group was $19.29 \pm 7.04$ $\mathrm{ng} / \mathrm{mL}$, which was significantly higher than that of the control group $(18.06 \pm 6.56 \mathrm{ng} / \mathrm{mL} ; \mathrm{p}=0.0072$; Figure $1 \mathrm{~A})$. Based on the endoscopic examination, the CRS group could divided into the two phenotypes and the serum $25(\mathrm{OH}) \mathrm{D}$ level was $18.95 \pm$ $0.71 \mathrm{ng} / \mathrm{mL}$ on CRS without nasal polyp and $19.35 \pm 1.21 \mathrm{ng} / \mathrm{mL}$ on CRS with nasal polyp, respectively (Figure 1B). There was no statistical difference for 25(OH)D level between CRS with nasal polyp and CRS without nasal polyp. As a categorical variable, sufficient serum $25(\mathrm{OH}) \mathrm{D}$ level was present in $9.76 \%$ of the CRS group compared to $5.57 \%$ of the normal group ( $p=0.0054$ ). Among deficient and insufficient serum 25(OH)D groups, the serum 25(OH)D level showed no significant difference between the CRS group and the control group. However, among sufficient serum 25(OH)D groups, the CRS group showed significantly higher $25(\mathrm{OH}) \mathrm{D}$ level than the control group $(p=0.0242$; Figure 1C).

\section{Relationship between serum 25(OH)D level and the} symptoms and signs of endoscopy-based CRS The serum 25(OH)D levels and all possible CRS symptom combinations were analyzed to identify relationships. The combinations including mucopurulent rhinorrhea at the middle meatus showed generally higher ORs with reliable $p$-values and had greater power of prediction for normal serum $25(\mathrm{OH})$ 
Table 3. Demographic information tum and NFIM $(n=75)$.

\begin{tabular}{|c|c|c|c|c|c|}
\hline & $\begin{array}{c}\text { Total } \\
\text { (N=30609) }\end{array}$ & $\begin{array}{l}\text { I (<20ng/mL) } \\
(\mathrm{N}=20485)\end{array}$ & $\begin{array}{c}\text { II }(\geq 20 \mathrm{ng} / \mathrm{mL}) \\
(\mathrm{N}=\mathbf{8 4 1 2})\end{array}$ & $\begin{array}{c}\text { III ( } \geq 3 \text { 30ng.mL) } \\
(\mathrm{N}=1712)\end{array}$ & p-value \\
\hline Vitamin D & $18.065 \pm 6.564$ & $14.364 \pm 3.362$ & $23.818 \pm 2.724$ & $34.089 \pm 3.914$ & $<.0001^{*}$ \\
\hline $\operatorname{Sex}(n, \%)$ & & & & & $<.0001^{*}$ \\
\hline Male & $13177(43.05)$ & 7748(37.82) & $4436(52.73)$ & $993(58)$ & \\
\hline Female & $17432(56.95)$ & $12737(62.18)$ & $3976(47.27)$ & $719(42)$ & \\
\hline Age (y) & $49.847 \pm 16.78$ & $47.435 \pm 16.39$ & $53.079 \pm 15.66$ & $56.803 \pm 14.71$ & $<.0001^{*}$ \\
\hline Smoking status, $\%$ & & & & & $<.0001^{*}$ \\
\hline former/nonsmoker & $6275(50.41)$ & $3657(48.15)$ & $2159(54.42)$ & $459(51.75)$ & \\
\hline Current & 6174(49.59) & $3938(51.85)$ & $1808(45.58)$ & $428(48.25)$ & \\
\hline Obesity & & & & & $<.0001^{*}$ \\
\hline$(-)$ & $20770(68.35)$ & $14025(69.04)$ & $5529(66.09)$ & $1216(71.28)$ & \\
\hline$(+)$ & $9617(31.65)$ & $6290(30.96)$ & $2837(33.91)$ & $490(28.72)$ & \\
\hline Education & & & & & $<.0001^{*}$ \\
\hline Low & $14886(49.40)$ & $9777(48.52)$ & $4210(50.78)$ & $899(53.13)$ & \\
\hline High & $15249(50.60)$ & $10375(51.48)$ & $4081(49.22)$ & 793(46.87) & \\
\hline Stress & & & & & $<.0001^{*}$ \\
\hline Light & $8290(27.58)$ & $5806(28.89)$ & $2081(25.11)$ & $403(23.90)$ & \\
\hline Heavy & $21776(72.42)$ & $14287(71.1)$ & $6206(74.89)$ & $1283(76.10)$ & \\
\hline Hypertension & & & & & $0.0003^{*}$ \\
\hline$(-)$ & $28787(95.63)$ & 19162(95.29) & $7992(96.31)$ & 1633(96.29) & \\
\hline$(+)$ & $1316(4.37)$ & $947(4.71)$ & $306(3.69)$ & $63(3.71)$ & \\
\hline Diabetes mellitus & & & & & $<.0001^{*}$ \\
\hline$(-)$ & $27685(91.96)$ & $18630(92.64)$ & $7535(90.81)$ & $1520(89.62)$ & \\
\hline$(+)$ & $2420(8.04)$ & $1481(7.36)$ & 763(9.19) & $176(10.38)$ & \\
\hline Stroke & & & & & $<.0001^{*}$ \\
\hline$(-)$ & 29500(97.99) & 19757(98.24) & $8095(97.55)$ & $1648(97.23)$ & \\
\hline$(+)$ & $604(2.01)$ & $354(1.76)$ & $203(2.45)$ & $47(2.77)$ & \\
\hline Bronchial Asthma & & & & & 0.0533 \\
\hline$(-)$ & $28814(95.71)$ & 19283(95.88) & $7923(95.48)$ & $1608(94.81)$ & \\
\hline$(+)$ & 1291(4.29) & $828(4.12)$ & $375(4.52)$ & $88(5.19)$ & \\
\hline Allergic rhinitis & & & & & $0.0015^{*}$ \\
\hline$(-)$ & 26306(95.13) & $17386(94.81)$ & 7390(95.86) & $1530(95.27)$ & \\
\hline$(+)$ & $1346(4.87)$ & $951(5.19)$ & $319(4.14)$ & $76(4.73)$ & \\
\hline Ca intake / day & $490.245 \pm 339.548$ & $487.236 \pm 346.223$ & $509.014 \pm 337.577$ & $500.204 \pm 349.682$ & $<.0001^{*}$ \\
\hline Cholesterol & $188.509 \pm 36.345$ & $187.667 \pm 36.602$ & $190.153 \pm 35.459$ & $188.577 \pm 35.409$ & $<.0001^{*}$ \\
\hline $\mathrm{HbA} 1 \mathrm{c}$ & $5.995 \pm 1.113$ & $5.948 \pm 1.109$ & $6.063 \pm 1.076$ & $6.242 \pm 1.028$ & $<.0001^{*}$ \\
\hline
\end{tabular}

* Statistically significant $(p<0.05)$.

$D$ level than other combinations. These combinations included mucopurulent rhinorrhea at the middle meatus on endoscopic finding with the following symptoms: anterior/posterior nasal drip and facial pain, anterior/posterior nasal drip and loss of smell, nasal obstruction and anterior/posterior nasal drip and loss of smell, anterior/posterior nasal drip and facial pain and loss of smell, and nasal obstruction and anterior/posterior nasal drip and facial pain and loss of smell (Figure 2, Table 3). Unlike mucopurulent rhinorrhea at the middle meatus on endoscopic exam, the combinations including nasal polyp on endoscopic examination did not show significant ORs relevant to serum 25(OH)D level.

\section{Discussion}

CRS is a common condition affecting $6.95 \%$ of the adult population, in which the sinuses become inflamed status for at 
Table 4. Logistic regression of demographic factors.

\begin{tabular}{|c|c|c|c|c|c|c|c|c|}
\hline \multirow[t]{2}{*}{ Variable } & \multicolumn{4}{|c|}{ Univariable } & \multicolumn{4}{|c|}{ Multivariable (Stepwise) } \\
\hline & \multirow[t]{2}{*}{ OR } & \multicolumn{2}{|c|}{$95 \% \mathrm{Cl}$} & p-value & OR & \multicolumn{2}{|c|}{$95 \% \mathrm{CI}$} & \multirow[t]{2}{*}{ p-value } \\
\hline $\operatorname{Sex}(n, \%)$ & & & & & & & & \\
\hline Female vs Male & 0.526 & 0.502 & 0.552 & $<.0001$ & 0.526 & 0.5 & 0.553 & $<.0001$ \\
\hline Age (y) & 1.025 & 1.023 & 1.026 & $<.0001$ & 1.025 & 1.024 & 1.027 & $<.0001$ \\
\hline \multicolumn{9}{|l|}{ Smoking status, \% } \\
\hline Current vs former/nonsmoker & 0.808 & 0.752 & 0.867 & $<.0001$ & & & & \\
\hline \multicolumn{9}{|l|}{ Obesity } \\
\hline$(+)$ vs (-) & 1.079 & 1.026 & 1.135 & 0.003 & & & & \\
\hline \multicolumn{9}{|l|}{ Education } \\
\hline High vs Low & 0.895 & 0.854 & 0.939 & $<.0001$ & & & & \\
\hline \multicolumn{9}{|l|}{ Stress } \\
\hline Heavy vs Light & 1.225 & 1.161 & 1.293 & $<.0001$ & & & & \\
\hline \multicolumn{9}{|l|}{ Hypertension } \\
\hline$(+)$ vs (-) & 0.779 & 0.69 & 0.88 & $<.0001$ & & & & \\
\hline \multicolumn{9}{|l|}{ Diabetes mellitus } \\
\hline$(+)$ vs $(-)$ & 1.309 & 1.204 & 1.424 & $<.0001$ & & & & \\
\hline \multicolumn{9}{|l|}{ Stroke } \\
\hline$(+)$ vs (-) & 1.431 & 1.219 & 1.68 & $<.0001$ & & & & \\
\hline \multicolumn{9}{|l|}{ Bronchial Asthma } \\
\hline$(+)$ vs $(-)$ & 1.141 & 1.017 & 1.279 & 0.0243 & & & & \\
\hline \multicolumn{9}{|l|}{ Allergic rhinitis } \\
\hline$(+)$ vs (-) & 0.82 & 0.728 & 0.923 & 0.001 & 0.825 & 0.731 & 0.932 & 0.0019 \\
\hline Ca intake / day (100 unit) & 1.016 & 1.009 & 1.023 & $<.0001$ & & & & \\
\hline Cholesterol & 1.002 & 1.001 & 1.002 & $<.0001$ & & & & \\
\hline $\mathrm{HbA} 1 \mathrm{c}$ & 1.118 & 1.083 & 1.154 & $<.0001$ & & & & \\
\hline
\end{tabular}

$\mathrm{OR}$, odd ratio; $\mathrm{Cl}$, confidence interval; * Statistically significant $(\mathrm{p}<0.05)$

least 12 weeks in South Korea ${ }^{(12)}$. Because 25(OH)D is known to have anti-inflammatory properties leading to reduced inflammation $^{(13-15)}$, we hypothesized that low $25(\mathrm{OH}) \mathrm{D}$ level is related to the increased prevalence of CRS. Although previous studies have suggested an association between serum 25(OH)D level and prevalence of $\mathrm{CRS}^{(7-9)}$, their results had some limitations by small sample sizes. Therefore, this study aimed to investigate the correlation between serum $25(\mathrm{OH}) \mathrm{D}$ level and CRS satisfying the diagnostic criteria of endoscopy-based CRS in adults using national health database from South Korea.

In contrast with previous studies, our results provided counterevidence to prior works on the association of 25(OH)D levels and CRS showing a higher serum 25(OH)D level in the CRS group than in the control group. Furthermore, the clogit regression analysis showed the endoscopic finding of mucopurulent rhinorrhea showed higher ORs with a greater power of prediction for normal 25(OH)D. While prior research has suggested a link between low 25(OH)D levels and development of CRS, our study showed low serum 25(OH)D levels were not associated with increased prevalence of CRS in Korean adults. Our results could be used to advance a new opinion against previous findings regarding correlations between low 25(OH)D level and increased prevalence of CRS. Until now, several previous studies have shown that $25(\mathrm{OH}) \mathrm{D}$ deficiency is associated with increased risk of CRS in adults ${ }^{(7-9)}$. Pinto measured serum $25(\mathrm{OH})$ $D$ levels in the clinical laboratory by using samples from urban African American and white adults with and without severe CRS and showed that serum 25(OH)D levels were significantly lower in urban African American subjects with CRS as compared with age- and sex-matched controls ${ }^{(7)}$. Furthermore, Wang showed that a significantly lower 25(OH)D level was found in a group of Taiwanese patients with CRS, revealing an association with greater nasal polyp size ${ }^{(9)}$. However, according to our results, endoscopy-based CRS was not an important predictor for low serum 25(OH)D level, in contrast with the previous study. The discrepancy in results regarding the relationship between 
A

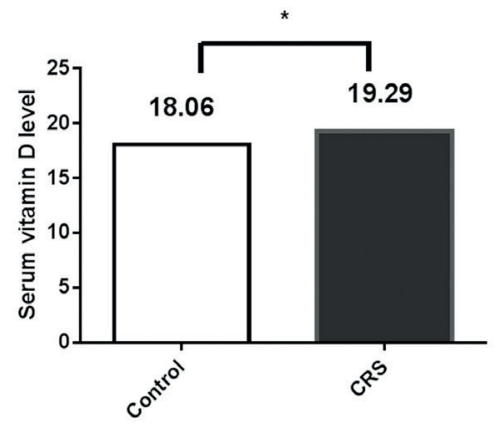

B

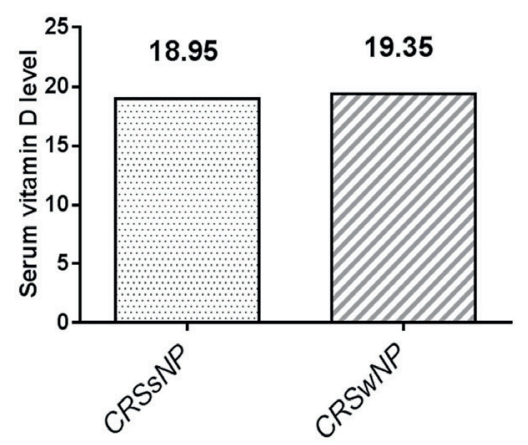

C

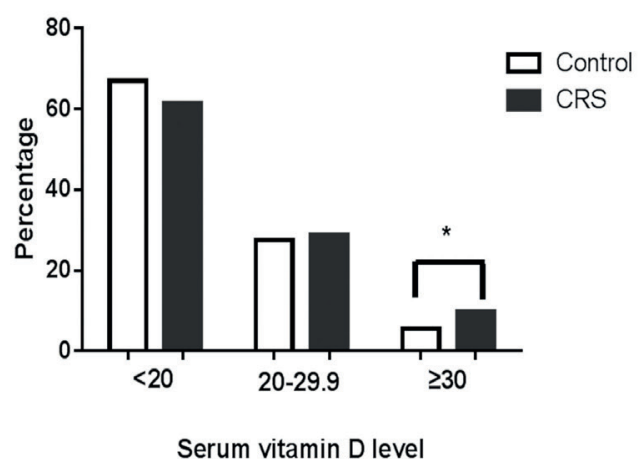

Figure 1. Comparison of 25(OH)D level between control and CRS groups. (a) As a continuous variable, the serum 25(OH)D level in the CRS group was significantly higher than that of the control group. (b) There was no statistical difference for 25(OH)D level between CRS with nasal polyp and CRS without nasal polyp. (c) As a categorical variable, the serum $25(\mathrm{OH}) \mathrm{D}$ level was significantly higher in the CRS group than in the control group only in the sufficient serum $25(\mathrm{OH}) \mathrm{D}$ group. The unit of $25(\mathrm{OH}) \mathrm{D}$ is $\mathrm{ng} / \mathrm{mL}$. $\mathrm{CRS}=$ chronic rhinosinusitis.
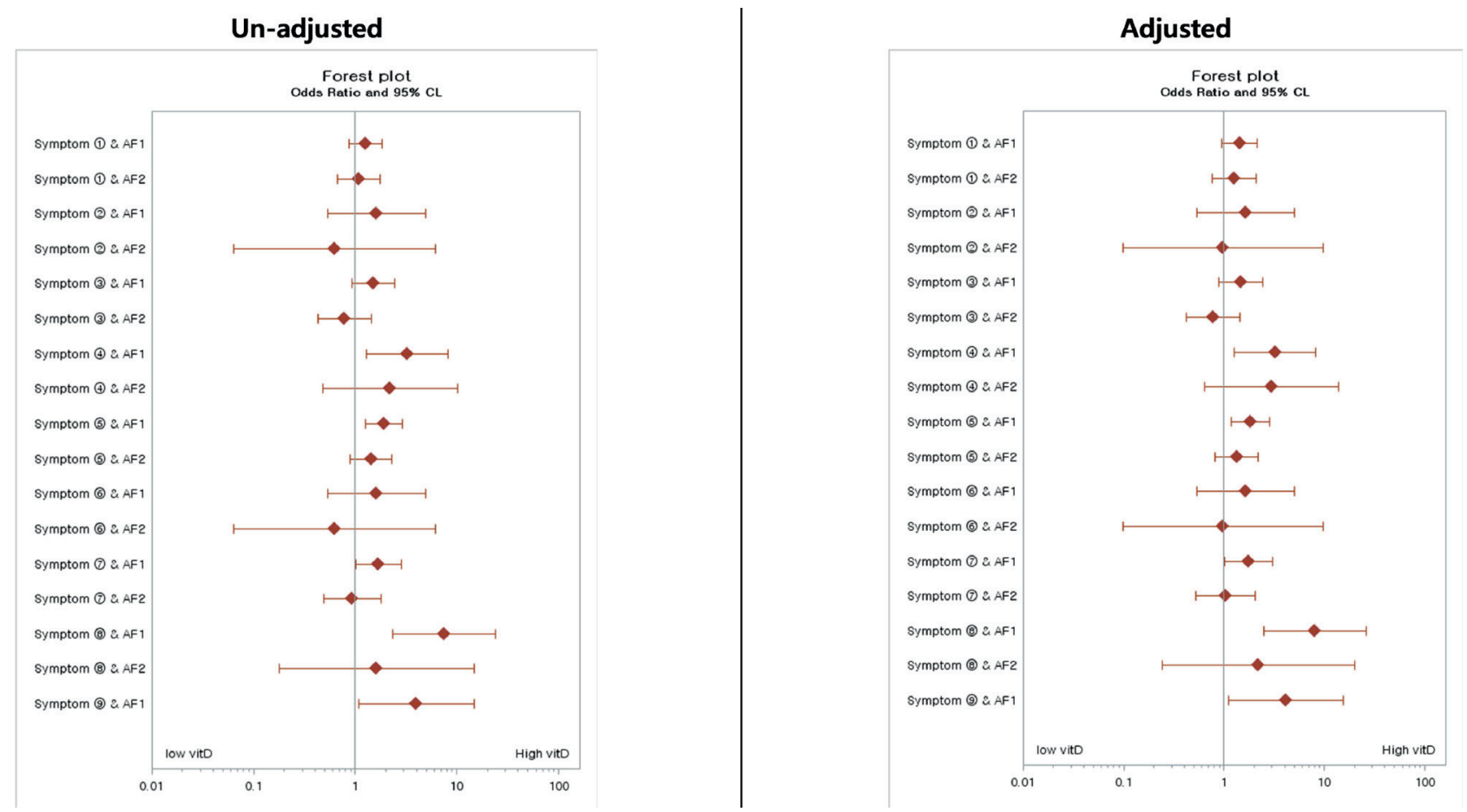

Figure 2. Relative importance of 25(OH)D level according to endoscopy-based CRS. The combinations including mucopurulent rhinorrhea at the middle meatus (AF1) showed generally higher serum 25(OH)D levels with high odds ratios. However, the combinations including nasal polyps on endoscopic exam (AF2) did not show significant odds ratios relevant to serum 25(OH)D level. S1, nasal obstruction and anterior/posterior nasal drip; S2, nasal obstruction and facial pain; S3, nasal obstruction and loss of smell; S4, anterior/posterior nasal drip and facial pain; S5, anterior/posterior nasal drip and loss of smell; S6, nasal obstruction, anterior/posterior nasal drip, and facial pain; S7, nasal obstruction, anterior/posterior nasal drip, and loss of smell; S8, anterior/posterior nasal drip, facial pain, and loss of smell; S9, nasal obstruction, anterior/posterior nasal drip, facial pain, and loss of smell; AF1, endoscopic finding of mucopurulent rhinorrhea at the middle meatus; AF2, endoscopic finding of nasal polyps.

serum 25(OH)D level and CRS might be explained as follows. First, the composition of the study population, including different races or sun exposure times, varies by country, resulting in different associations between serum 25(OH)D level and CRS prevalence. Second, while previous studies has some limitations by small sample sizes, our study includes a larger data set, which may help clarify the relationship between serum 25(OH)D level and CRS. Furthermore, unlike previous studies, this epidemiological study considered various demographic factors including sex, age, and allergic rhinitis which may affect serum $25(\mathrm{OH})$ 
D levels. Third, the definition of CRS varied among studies; several guidelines and tools were used to diagnose CRS cohorts, whereas some studies made the diagnosis based on their own clinical and radiographic finding $\mathrm{s}^{(7-9,16)}$. Also, previous studies included severe cases of CRS, which showed stage IV disease on computed tomographic analysis graded by the Harvard criteria ${ }^{(7)}$. The inclusion of only severe cases of CRS seems to have limited application for all cases of CRS, while the endoscopybased CRS definition used in our study might be more reasonable because of the use of objective findings such as mucopurulent rhinorrhea or nasal polyp.

In this study, serum 25(OH)D level ranged from minimum of 1.98 $\mathrm{ng} / \mathrm{mL}$ to maximum of $66.96 \mathrm{ng} / \mathrm{mL}$, with mean serum $25(\mathrm{OH})$ D level of $18.065( \pm 6.564) \mathrm{ng} / \mathrm{mL}$ and median value of $17.08 \mathrm{ng} /$ $\mathrm{mL}$. Cut-off values for extremely low serum $25(\mathrm{OH}) \mathrm{D}$ levels were measured according to existing literature ${ }^{(11)}$. Possibly, serum $25(\mathrm{OH}) \mathrm{D}$ level would have to be reduced to a highly significant level to result in clinically effective decrease in sinonasal immunity, as demonstrated by murine CRS animal models. Mulligan et al. showed that both $25(\mathrm{OH}) \mathrm{D}$ deficiency and Aspergillus fumigatus CRS mouse model were associated with altered sinonasal 25(OH)D metabolism, which caused reductions in local levels of active $25(\mathrm{OH}) \mathrm{D}$ metabolite even with adequate circulating $25(\mathrm{OH}) \mathrm{D}$ levels $\mathrm{s}^{(17)}$. This experiment proved that the deficiency of circulating serum $25(\mathrm{OH}) \mathrm{D}$ level was not associated with CRS, which coincide with our results.

Recent findings on the function of $25(\mathrm{OH}) \mathrm{D}$ may explain aspects of the pathophysiology of various allergic diseases including allergic rhinitis and asthma ${ }^{(18,19)}$. Sultan et al. showed that sinonasal epithelial cells can generate active $25(\mathrm{OH}) \mathrm{D}$, which can increase the expression of antimicrobial peptides such as cathelicidin ${ }^{(20)}$. This study suggests that $25(\mathrm{OH}) \mathrm{D}$ can act as an immune-modulating agent in host defense. Meanwhile, the role of $25(\mathrm{OH}) \mathrm{D}$ in the pathogenesis of inflammatory airway diseases such as chronic rhinosinusitis remains under investigation. Studies performed in Sao Paulo and Belgium could not reveal a relationship between sinusitis and chronic rhinitis ${ }^{(21,22)}$. Whereas, allergic rhinitis was considered as the most important risk factor of CRS in South Korea ${ }^{(23)}$. In other words, the Asiatic pathophysiology of CRS may differ from the European type, due to a synergism with allergic rhinitis ${ }^{(24)}$. Among demographic factors of this study, we found that female sex, low age, and allergic rhinitis were significant factors showing lower $25(\mathrm{OH})$ $\mathrm{D}$ levels. This result coincides with that of a previous study from South Korea on the association between lower serum 25(OH)D level and higher allergic rhinitis prevalence ${ }^{(25)}$. In regards to the association between allergic rhinitis and low serum 25(OH)D level, the conclusions from this epidemiologic study based on a large population made the opposite argument against previous work on the role of $25(\mathrm{OH}) \mathrm{D}$ in $\mathrm{CRS}$, which was limited by a small number of shortcoming ${ }^{(7-9)}$. Systematic review showed that low serum 25(OH)D is more prevalent in patients with CRSwNP and in patients with eosinophilic or allergic fungal rhinosinusitis, although no definitive conclusion can be made on whether $25(\mathrm{OH}) \mathrm{D}$ is a causative factor in $\mathrm{CRS}^{(26)}$. We also identified some racial difference regarding the prevalence of $25(\mathrm{OH}) \mathrm{D}$ deficiency, and our results support that the Asiatic pathophysiology of CRS about serum 25(OH)D deficiency may differ from the European type. Therefore, this study reflected that the effect of serum 25(OH)D level on CRS can show different pathophysiology in South Korea, although the available evidence indicated a significant relationship between low $25(\mathrm{OH}) \mathrm{D}$ levels and CRS phenotypes.

Our study has some limitations. First, although the KNHANES is a large and complex survey, the sample size of CRS patients might be a limitation. The number of patients with CRS is quite small compared with controls. Second, this study is purely observational and epidemiological, like previous studies. Despite the nature of this study, CRS diagnosis was based on questionnaires about nasal symptoms along with positive endoscopic findings, such as mucopurulent rhinorrhea at the middle meatus or nasal polyp on endoscopy confirmed by otorhinolaryngology residents. As we chose objective diagnostic criteria of CRS using endoscopic findings compared to previous studies, the diagnostic criteria of endoscopy-based CRS could be considered more reasonable. Since there have been several arguments about this topic, further evidence of a causal or therapeutically-relevant linkage between 25(OH)D and CRS is required. Third, previous epidemiological studies have demonstrated ethnic and regional differences in $25(\mathrm{OH}) \mathrm{D}$ levels. In this study, the mean serum $25(\mathrm{OH}) \mathrm{D}$ level of individuals from South Korea was $19.48 \mathrm{ng} /$ $\mathrm{mL}$, whereas the mean serum $25(\mathrm{OH}) \mathrm{D}$ levels of individuals from the US and Canada are greater than $24 \mathrm{ng} / \mathrm{mL}^{(27-29)}$. Only $5.59 \%$ of participants showed serum $25(\mathrm{OH}) \mathrm{D}$ levels of $30 \mathrm{ng} / \mathrm{mL}$ or greater and this phenomenon may be influenced by indoor lifestyle and reduced light exposure time in South Korea. Because the skin pigmentation and national vitamin D food fortification programs are different according to nations, geographic and environmental effects on serum 25(OH)D level should be considered for future study.

\section{Conclusion}

In spite of some limitations, we found that the level of serum 25(OH)D level was higher in patients with CRS than without CRS from the 2008 to 2011 KNHANES in adults from South Korea. This means that serum $25(\mathrm{OH}) \mathrm{D}$ deficiency is not a possible risk factor in Korean adults with CRS contradicting those of previous studies. This study is the first epidemiological study to be conducted on the relationship between 25(OH)D and CRS, and it allows for meaningful questioning of previous findings of positive correlations between low 25(OH)D levels and CRS prevalence. 


\section{Authorship contribution}

EJL: study concept and design; drafting of manuscript; manuscript revision. $\mathrm{CSH}$ : acquisition, analysis, and interpretation of data; approval of final version of manuscript to be published. K-SK: study concept and design; revision of manuscript; analysis and interpretation of data; approval of final version of manuscript to be published.

\section{Conflict of interest}

All authors declared no conflicts of interest.

\section{References}

1. Wjst M, Hyppnen E. 25(OH)D serum levels and allergic rhinitis. Allergy. 2007;62(9):1085-6.

2. Jung JW, Kim JY, Cho SH, Choi BW, Min $\mathrm{KU}$, Kang HR. Allergic rhinitis and serum 25-hydroxy25(OH)D level in Korean adults. Ann Allergy Asthma Immunol. 2013:111(5):352-7.

3. Arshi S, Ghalehbaghi B, Kamrava SK, Aminlou M. 25(OH)D serum levels in allergic rhinitis: any difference from normal population? Asia Pac Allergy. 2012;2(1):45-8.

4. Erkkola M, Kaila M, Nwaru BI, KronbergKippilä C, Ahonen S, Nevalainen J, et al. Maternal vitamin $D$ intake during pregnancy is inversely associated with asthma and allergic rhinitis in 5-year-old children. Clin Exp Allergy. 2009;39(6):875-82.

5. Camargo CA Jr, Ganmaa D, Frazier AL, Kirchberg FF, Stuart JJ, Kleinman K, et al. Randomized trial of vitamin $D$ supplementation and risk of acute respiratory infection in Mongolia. Pediatrics. 2012;130(3):e561-7.

6. Bergman $P$, Lindh AU, Björkhem-Bergman $L$, Lindh JD. Vitamin $D$ and respiratory tract infections: a systematic review and metaanalysis of randomized controlled trials PLoS One. 2013;8(6):e65835.

7. Pinto JM, Schneider J, Perez R, DeTineo M Baroody FM, Naclerio RM. Serum 25-hydroxyvitamin D levels are lower in urban African American subjects with chronic rhinosinusitis. J Allergy Clin Immunol. 2008;122(2):4157.

8. Mulligan JK, White DR, Wang EW, Sanson SR, Moses H, Yawn RJ, et al. Vitamin D3 deficiency increases sinus mucosa dendritic cells in pediatric chronic rhinosinusitis with nasal polyps. Otolaryngol Head Neck Surg. 2012;147(4):773-81.

9. Wang LF, Lee CH, Chien CY, Chen JY, Chiang FY, Tai CF. Serum 25-hydroxyvitamin D levels are lower in chronic rhinosinusitis with nasal polyposis and are correlated with disease severity in Taiwanese patients. Am J Rhinol Allergy. 2013;27(6):e162-5.

10. Kim JH, Cho C, Lee EJ, Suh YS, Choi BI, Kim KS. Prevalence and risk factors of chronic rhinosinusitis in South Korea according to diagnostic criteria. Rhinology. 2016;54(4):329-35.
11. Dawson-Hughes B, Heaney RP, Holick MF, Lips P, Meunier PJ, Vieth R. Estimates of optimal vitamin D status. Osteoporos Int. 2005;16(7):713-6.

12. Kim YS, Kim NH, Seong SY, Kim KR, Lee GB, Kim KS. Prevalence and risk factors of chronic rhinosinusitis in Korea. Am J Rhino Allergy. 2011;25(3):117-21

13. Wu S, Sun J. Vitamin D, vitamin D receptor, and macroautophagy in inflammation and infection. Discov Med. 2011;11(59):325-35.

14. Sun J. Vitamin D and mucosal immune function. Curr Opin Gastroenterol. 2010;26(6):591-5.

15. Huang H, Porpodis K, Zarogoulidis P, Domvr K, Giouleka P, Papaiwannou A, et al. Vitamin $D$ in asthma and future perspectives. Drug Des Devel Ther. 2013;7:1003-13.

16. Stokes PJ, Rimmer J. The relationship between serum vitamin $D$ and chronic rhinosinusitis: A systematic review. Am J Rhinol Allergy. 2016;30(1):23-8.

17. Mulligan JK, Pasquini WN, Carroll WW Williamson $\mathrm{T}$, Reaves $\mathrm{N}$, Patel $\mathrm{KJ}$, et al. Dietary vitamin D3 deficiency exacerbates sinonasal inflammation and alters local 25(OH)D3 metabolism. PLoS One. 2017;12(10):e0186374.

18. Abuzeid WM, Akbar NA, Zacharek MA Vitamin D and chronic rhinitis. Curr Opin Allergy Clin Immunol. 2012;12(1):13-7.

19. Yawn J, Lawrence LA, Carroll WW, Mulligan JK. Vitamin D for the treatment of respiratory diseases: is it the end or just the beginning? J Steroid Biochem Mol Biol. 2015;148:326-37.

20. Sultan B, Ramanathan M Jr, Lee J, May L, Lane AP. Sinonasal epithelial cells synthesize active vitamin $D$, augmenting host innate immune function. Int Forum Allergy Rhinol. 2013:3(1):26-30

21. Pilan RR, Pinna FR, Bezerra TF, Mori RL, Padua FG, Bento RF, et al. Prevalence of chronic rhinosinusitis in Sao Paulo. Rhinology. 2012;50(2):129-38.

22. Bachert C, van Cauwenberge P, Olbrecht J, van Schoor J. Prevalence, classification and perception of allergic and nonallergic rhinitis in Belgium. Allergy. 2006:61(6):693-8.

23. Kim YS, Kim NH, Seong SY, Kim KR, Lee GB, Kim KS. Prevalence and risk factors of chronic rhinosinusitis in Korea. Am J Rhinol
Allergy. 2011;25(3):117-21.

24. Beule A. Epidemiology of chronic rhinosinusitis, selected risk factors, comorbidities, and economic burden. GMS Curr Top Otorhinolaryngol Head Neck Surg. 2015;14:Doc11.

25. Kim YH, Kim KW, Kim MJ, Sol IS, Yoon SH, Ahn HS, et al. Vitamin D levels in allergic rhinitis: a systematic review and meta-analysis. Pediatr Allergy Immunol. 2016;27(6):580-90.

26. Stokes PJ, Rimmer J. The relationship between serum vitamin $D$ and chronic rhinosinusitis: A systematic review. Am J Rhinol Allergy. 2016;30(1):23-8.

27. Ginde AA, Liu MC, Camargo CA Jr. Demographic differences and trends of vitamin D insufficiency in the US population, 1988-2004. Arch Intern Med. 2009;169(6):626-32

28. Rizzoli R, Eisman JA, Norquist J, Ljunggren O, Krishnarajah G, Lim SK, et al. Risk factors for vitamin $D$ inadequacy among women with osteoporosis: an international epidemiological study. Int J Clin Pract. 2006;60(8):1013-9.

29. Choi HS, Oh HJ, Choi H, Choi WH, Kim JG, Kim KM, et al. Vitamin D insufficiency in Korea--a greater threat to younger generation: the Korea National Health and Nutrition Examination Survey (KNHANES) 2008. J Clin Endocrinol Metab. 2011;96(3):643-51.

Kyung-Su Kim

Department of Otorhinolaryngology

Gangnam Severance Hospital

Yonsei University College of Medicine

211 Eonju-ro, Gangnam-gu, 135-720

Seoul

Republic of Korea

Tel: +82220193460

Fax: +82234634750

E-mail:ydrhinol@yuhs.ac 